\title{
A família, o cuidar e o desenvolvimento da criança autista
}

\section{The family inserted in the growth and development of the autistic child}

Silvio Eder Dias da Silva ${ }^{1}$, Arielle Lima dos Santos ${ }^{2}$, Yasmim Martins de Sousa ${ }^{2}$, Natacha Mariana Farias da Cunha ${ }^{3}$, Joel Lobato da Costa ${ }^{4}$, Jeferson Santos Araújo ${ }^{5}$

1. Docente da Faculdade de Enfermagem da Universidade Federal do Pará (UFPA), Belém, PA, Brasil. 2. Mestranda pelo Programa de Pós-graduação em Enfermagem (PPGENF) pela Universidade Federal do Pará (UFPA), Belém, PA, Brasil. 3. Mestre em enfermagem pelo Programa de Pós-graduação em Enfermagem (PPGENF) pela Universidade Federal do Pará (UFPA), Belém, PA, Brasil 4. Mestrando pelo Programa de Pós-graduação em Enfermagem (PPGENF) pela Universidade Federal do Pará (UFPA), Belém, PA, Brasil. 5. Docente no Curso de Saúde Coletiva da Universidade Federal do Sul e Sudeste do Pará (UNIFESSPA), Marabá, PA, Brasil.

\section{Resumo}

Introdução: O Autismo é considerado como um transtorno global do desenvolvimento que se inicia antes dos três anos de idade. Caracteriza-se como uma síndrome comportamental de etiologias múltiplas que compromete o processo do desenvolvimento infantil. Objetivo: identificar o que se tem produzido na literatura científica sobre o cuidar em famílias de crianças com transtorno invasivo do desenvolvimento. Método: Estudo de descritivo com abordagrm qualitativa, sendo uma revisão integrativa. Resultados: permitiram identificar que as famílias têm grandes dificuldades em manter suas estratégias para o desenvolvimento do autocuidado de crianças com autismo. Foi identificada, neste estudo, a escassez de produção científica sobre autorias de enfermeiro acerca desta temática. Conclusão: A análise de dados aponta para as estratégias adotadas por pais e familiares cuidadores, em busca do desenvolvimento adequado da criança autista.

Palavras-chave: Transtorno autistíco. Família. Psicologia Social. Cuidar.

\begin{abstract}
Introduction: Autism is considered as a global developmental disorder that begins before the age of three. It is characterized as a behavioral syndrome of multiple etiologies that compromises the process of infantile development. Objective: To identify what has been produced in the scientific literature on caring in families of children with invasive developmental disorders. Method: Descriptive study with qualitative approach, being an integrative review. Results: allowed to identify that families have great difficulties in maintaining their strategies for the development of self-care of children with autism. It was identified, in this study, the scarcity of scientific production on authorship of nurses on this subject. Conclusion: The analysis of data points to the strategies adopted by parents and family caregivers, in search of the adequate development of the autistic child.
\end{abstract}

Key words: Autistic disorder. Family. Social Psychology. Take care.

\section{INTRODUÇÃO}

O Autismo é considerado como um transtorno global do desenvolvimento que se inicia antes dos três anos de idade. Caracteriza-se como uma síndrome comportamental de etiologias múltiplas que compromete o processo do desenvolvimento infantil ${ }^{1}$.

A Organização Mundial de Saúde (OMS) estima que cerca de $1 \%$ da população mundial, sendo uma a cada 68 crianças com autismo, o que significa, em valores absolutos, algo em torno de 70 milhões de pessoas.

No Brasil, embora não se tenham ainda dados estatísticos oficiais, estima-se que cerca de $10 \%$ a $20 \%$ de crianças e adolescentes sofram de transtornos mentais, e que cerca de $3 \%$ a $4 \%$ desses transtornos necessitem de tratamentos intensivos ${ }^{2}$.

O transtorno do espectro do autismo, também conhecido por autismo, é um dos males mais frequentes na infância, definido pela presença de sintomas que começam na infância, percebidos tipicamente antes dos três anos de idade, e que comprometem a capacidade dessas crianças nas suas funções diárias. Tais sintomas são reconhecidos como os déficits sociais e de comunicação e de comportamentos fixos e repetitivos ${ }^{3}$.

A descoberta de uma patologia, deficiência ou alteração em uma criança traz repercussões na vida dos pais e, frequentemente, também mudanças significativas na vida das mães que assumem a responsabilidade de cuidar de uma criança. Assim também acontece com a família de uma criança autista ${ }^{4}$.

As crianças com autismo, enquanto portadoras de uma condição crônica, enfrentam dificuldades importantes no que tange à realização de tarefas comuns, próprias da sua fase de desenvolvimento; isso porque as características clínicas da síndrome afetam as condições físicas e mentais do indivíduo, aumentando a demanda por cuidados e, consequentemente, o 
nível de dependência de pais e/ou cuidadores. A família dessas crianças, por sua vez, vê-se diante do desafio de ajustar seus planos e expectativas futuras às limitações da condição, além da necessidade intransponível de adaptar-se à intensa dedicação e à prestação de cuidados das necessidades específicas do filho ${ }^{5}$.

Somadas a essas dificuldades, as pessoas com autismo também se deparam com limitações na realização de atividades diárias, como higiene e alimentação, as quais podem estar associadas aos comportamentos rígidos, agressivos ou repetitivos apresentados por eles. Em decorrência disso, a necessidade de cuidados diferenciados e a dependência dos pais e demais cuidadores é acentuada, levando a família a constantes mudanças em sua rotina a fim de se adaptar às características do familiar da criança com autismo.

A família é o grupo primário por excelência, porque a pessoa, desde o nascimento está imersa nele. É onde ela vive e desenvolve a experiência e habilidades que servirão como uma base para a vida em todas as áreas da sua existência. Também delimitada por grupo de afetividade, sangue ou ligação adotiva em que a partir dos contatos, interações contínuas e comunicativas permitem o desenvolvimento de estabilidade, a coesão, bem como a possibilidade de progresso evolutivo como as necessidades de cada um dos seus membros e sempre dependendo do ciclo de vida do sistema de família ${ }^{6}$.

O autismo, quando se manifesta, afeta toda a família, pois o processo de enfrentamento desencadeia mudanças em toda a dinâmica familiar, em especial na relação mãe e filho. As mães de crianças autistas, diante da situação de vulnerabilidade e de dependência do filho, passam a dedicar-se integralmente a eles, acumulando muitas responsabilidades, como os cuidados com a casa, com a família e ainda com o filho autista, o que acarreta grande sobrecarga emocional e física7.

A enfermagem, enquanto profissão, cuja ferramenta principal de trabalho é o cuidado, deve focar sua atenção nas crianças autistas e em suas mães, bem como nos cuidadores, cujo sofrimento pode estar encoberto pelo próprio existir do filho. Essas mães necessitam de atenção para que possam cuidar de seus filhos e de si mesmas participando ativamente do processo de tratamento ${ }^{8}$.

Assim, é importante apontar que as demandas e as necessidades das famílias se modificam ao longo dos anos. Em cada fase do desenvolvimento, surgem novas demandas, sendo que muitas são semelhantes àquelas que as famílias de crianças com desenvolvimento típico apresentam. Contudo, as famílias que têm filhos com necessidades especiais também enfrentam as exigências advindas da própria condição de deficiência da criança.

Frente a esse contexto, questiona-se o que tem sido apresentado pela literatura sobre as estratégias de famílias de crianças com transtorno invasivo do desenvolvimento.
Para responder a esse questionamento, objetivamos identificar neste estudo o que tem sido produzido na literatura científica no campo da saúde sobre autismo.

Apesar da relevância desse tema, observa-se ainda ser escasso o número de publicações científicas sobre o cuidado de crianças com transtorno invasivo do desenvolvimento na perspectiva de seus familiares. Esse mesmo estudo demonstrou que a produção científica brasileira sobre Transtorno do Espectro Autista (TEA) não atende à demanda do país.

Considerando a conceituação psicodinâmica do autismo e reconhecendo a complexidade da situação familiar, o presente estudo consiste em uma revisão da literatura científica sobre os desafios vivenciados pelas famílias de crianças com TEA e estratégias utilizadas para o desenvolvimento do cuidar de seus filhos.

\section{METODOLOGIA}

O estudo foi realizado na perspectiva do paradigma indutivo, pautando-se na revisão integrativa devido ao rigor preconizado em suas etapas: 1-Definição da pergunta de estudo; 2-estabelecimento de critérios de inclusão e busca na literatura; 3-definição das informações a serem extraídas da avaliação dos estudos a serem incluídos na revisão; 4-interpretação e apresentação dos resultados. Trata-se de um desenho de pesquisa que busca a apresentação sobre o panorama do conhecimento produzido e o desenvolvimento dessa área de pesquisa, mapeando a produção científica e apontando possíveis lacunas ${ }^{9}$.

As seguintes bases de dados foram utilizadas para a busca dos estudos incluídos na revisão: LILACS (Literatura LatinoAmericana e do Caribe em Ciências da Saúde); PSICOINFO (Biblioteca virtual de Psicologia); BDEnf (Base de Dados de Enfermagem), portal PUBMED (National Library of medicine), Cochrane Database. Seguindo os seguintes critérios de inclusão: artigos publicados nos idiomas Inglês; Espanhol e Português, na forma de texto completo que abordassem a temáticas relacionando a vivência de Mães, familiares e cuidadores de crianças com transtorno do desenvolvimento.

Como estratégia de busca, empregaram-se descritores previamente submetidos aos índices de descritores da DeCS (Descritores em Ciências da Saúde): Transtorno Autístico, Famílias, Mães, Enfermagem. E os mesmos descritores em idioma inglês, referenciado pelo Medical Subject Headings (MeSH): Autistic Disorder, Families, Mothers, Nursing.

Após a identificação, realizou-se a seleção dos estudos primários, de acordo com a questão norteadora e os critérios de inclusão previamente definidos. Todos os estudos identificados por meio da estratégia de busca foram inicialmente avaliados por meio da análise dos títulos seguidos pela leitura dos resumos. Nos casos em que os títulos e os resumos não se mostraram 
suficientes para definir a seleção inicial, procedeu-se à leitura na íntegra da publicação.

Os artigos classificados foram submetidos ao julgamento dos seus níveis de evidências. Sistema esse caracterizado hierarquicamente com seu grau de evidência baseado na abordagem metodológica que foi seguida para o desenvolvimento do estudo.

Em 1998, estudiosos de enfermagem elaboraram uma classificação hierárquica das evidências para a avaliação de pesquisas ou outras fontes de informação, baseadas na categorização da Agency for Healthcare Research and Quality (AHRQ) dos Estados Unidos da América. A qualidade das evidências é classificada em seis níveis, a saber. Nível 1 - Metanálise de múltiplos estudos controlados. Nível 2 Estudo individual com delineamento experimental; Nível 3-Estudo com delineamento quase experimental como estudo sem randomização com grupo único pré e pós-teste, séries temporais ou caso-controle; Nível 4 - Estudo com delineamento não experimental como pesquisa descritiva correlacionar e qualitativa ou estudos de caso; Nível 5 - Relatório de casos ou dado obtido de forma sistemática, de qualidade verificável ou dados de avaliação de programas. Nível 6 - opinião de autoridades respeitáveis baseada na competência clínica ou opinião de comitês de especialistas, incluindo interpretações de informações não baseadas em pesquisas ${ }^{9}$.

\section{RESULTADOS}

Inicialmente, realizou-se busca nas bases de dados acima mencionadas, resultando em 56 artigos, incluindo artigos em duplicatas. Em uma segunda fase de seleção, foram lidos os títulos e resumos, resultando na remoção de 39 artigos entre duplicatas e artigos que não atendiam adequadamente ao critério de inclusão, obtendo-se 17 artigos lidos criteriosamente, selecionando 10 artigos analisados, fazendo-se emergir as categorias temáticas.

O processo de seleção encontra-se sistematizado na figura que segue (Fiura 1):

Figura 1. Fluxograma de protocolo realizado na pesquisa. Belém, Pará, 2017.

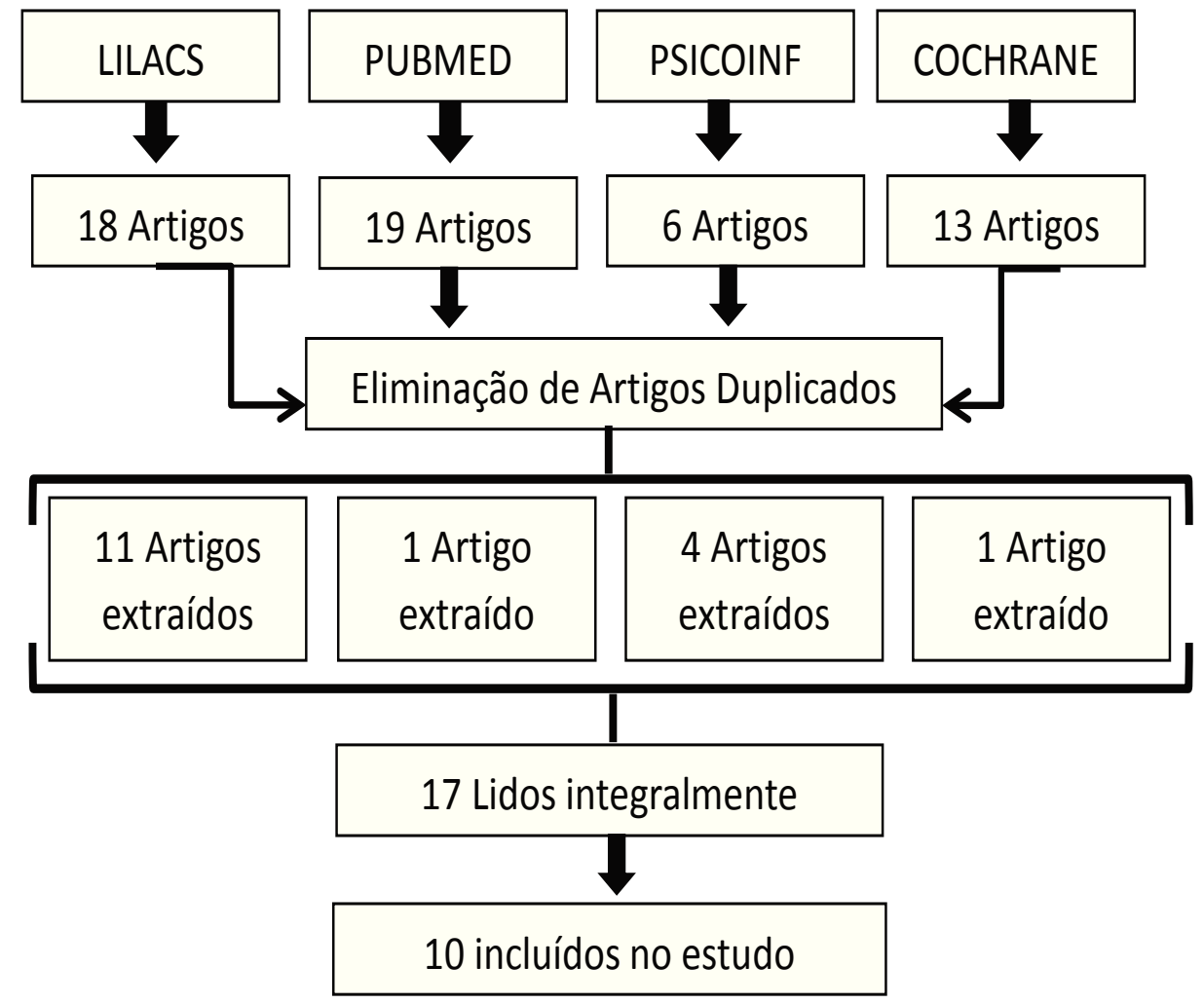

Dessa forma, essa revisão é composta por 10 artigos publicados entre 2008 a 2016 relativos aos últimos oito anos de pesquisa. Da amostra selecionada, nove estudos eram de natureza qualitativa e um quantitativo. Os artigos selecionados estão demonstrados no quadro abaixo, que contém informações de título, autoria, ano, e metodologia empregada, bem como seus resultados. Os artigos apresentados não se classificam por gêneros uma vez que retrata mães e cuidadores, sob a ótica do transtorno de desenvolvimento.

Tendo-se recorrido à análise das evidências apresentadas, foram criadas quatro categorias temáticas descritas como o autista dependente e a reorganização familiar, estratégia e intervenção. $O$ desenvolvimento do cuidar empregado ao autista, melhora apresentada no desenvolvimento as quais julgamos sintetizar o conhecimento da literatura pesquisada. 
Quadro 1. Síntese dos principais achados dos artigos selecionados

\begin{tabular}{|c|c|c|c|}
\hline PUBLICAÇÃO & AUTOR & MÉTODO & RESULTADOS \\
\hline $\begin{array}{l}\text { Vivências maternas na realidade de ter um filho autista: } \\
\text { uma compreensão pela enfermagem }\end{array}$ & Monteiro, et al, 2008 & Quali & $\begin{array}{l}\text { Revela que as mães vivenciam a facticidade de ter um } \\
\text { filho autista permeada por sentimentos de nulidade, fé e } \\
\text { solidão. As mães também deixam de viver o seu cotidiano } \\
\text { para viverem o cotidiano do filho. }\end{array}$ \\
\hline $\begin{array}{l}\text { A Vivência da Maternidade de Mães de Crianças com } \\
\text { Autismo }\end{array}$ & Smeha, et al, 2011. & Quali & $\begin{array}{l}\text { Apontam que está vivência é uma experiência } \\
\text { desafiadora. Essas mulheres renunciam à carreira } \\
\text { profissional, à vida social e às relações afetivas em prol } \\
\text { dos cuidados maternos. Surgem, com isso, sentimentos } \\
\text { como incerteza, tristeza e desamparo. }\end{array}$ \\
\hline $\begin{array}{l}\text { Sobrecarga Familiar e Crianças Com Transtornos do } \\
\text { Espectro do Autismo: Perspectiva dos Cuidadores }\end{array}$ & Misquiatti, et al, 2015. & Quali & $\begin{array}{l}\text { Índice de sobrecarga do familiar cuidador não fo } \\
\text { observada diferença estaticamente significante e indicou } \\
\text { que os grupos estavam moderadamente sobrecarregados } \\
\text { As características dos participantes também não foram } \\
\text { significantes no índice de sobrecarga. }\end{array}$ \\
\hline $\begin{array}{l}\text { Criando Pré-Escolares com Autismo: características e } \\
\text { desafios da coparentalidade }\end{array}$ & Sifuentes, et al.2010. & Quali. & $\begin{array}{l}\text { Demonstraram que as tarefas parentais não são } \\
\text { compartilhadas de forma igualitária entre o casal e que } \\
\text { isso ocorre em função das demandas próprias do autismo } \\
\text { e da forma como a família se organiza para atender a } \\
\text { essas demandas. }\end{array}$ \\
\hline
\end{tabular}

Famílias de crianças e adolescentes com autismo: cotidiano e realidade de cuidados em diferentes etapas do desenvolvimento
Matsukura, et al, 2015 Quali

Foi verificado que o cotidiano das famílias participantes se organiza em torno do membro com autismo, suas necessidades e dificuldades, aspecto observado tanto no ambiente doméstico como na realização de atividades externas, em outros contextos sociais
Cotidiano de famílias que convivem com o Autismo Infantil
Zanatta1, et., al, 2014.

Quali

Mostraram que conviver com o autismo é, para a família, uma tarefa árdua, difícil, cansativa e, por vezes, dolorosa. Também revelaram as dificuldades e o longo caminho percorrido pelos pais para chegar ao diagnóstico; trouxeram à tona o isolamento social que ocorre nas famílias, a sobrecarga materna física, psíquica e emocional.

Auto eficácia de cuidadores de crianças com o transtorno do espectro Autista

Tabaquim, et al, 2015.

Quali Demonstraram que os cuidadores possuíam um bom índice de Autoeficácia, com ausência de sobrecarga do cuidador.

Apontam-se as regularidades presentes nos discursos familiares em relação ao diagnóstico da deficiência,

Implicações de um diagnóstico: o que sentem as famílias dos sujeitos com deficiência?

Givigi, et al, 2015

Quali

Autismo infantil: Impacto do diagnóstico e repercussões nas relações familiares

Pinto, et al, 2016

Quali organizados posteriormente em 10 categorias: visão negativa (a rejeição, o susto, a tristeza, a agressividade, o preconceito, a dependência, o diferente, a dificuldade e a superproteção) e visão positiva (as potencialidades).

O impacto da revelação do diagnóstico de autismo para a família; características da revelação do diagnóstico: o local, o tempo e a relação dialógica entre o profissional e a família; alteração nas relações familiares e a sobrecarga materna no cuidado à criança autista

Evidenciaram que, para essas mães, a participação da criança na terapia de grupo significa a possibilidade de obter benefícios em sua convivência social e no seu
Significado da Terapia de grupo para crianças autistas:

Percepção das Mães
Simões, et al, 2010.
Quali desenvolvimento psicomotor e comportamental, bem como proporciona aos pais uma maior participação em seus cuidados e consequentemente a obtenção de maiores conhecimentos sobre este transtorno. 


\section{DISCUSSÃO}

\section{O autista dependente e a reorganização familiar}

Atualmente, o autismo infantil é considerado um transtorno global do desenvolvimento, manifestado antes dos três anos de idade e caracterizado pelo comprometimento de três áreas: a comunicação, a interação social e a presença de comportamento, interesses e atividades estereotipados e repetitivos ${ }^{10}$.

Dessa forma durante o levantamento dos estudos, é possível afirmar que as condutas inerentes ao comportamento já delineado da criança autista são um dos fatores mais estressores das mães e cuidadores dessas crianças.

Outro fator de forte impacto dentro dos estudos é apontado por dificuldades em relação à dependência no comportamento desafiador do autista. As birras e as autoagressões do filho, esses fatores estão presentes em cerca de $60 \%$ dos artigos e fazem referências a esses fatores. Os estudos mostram ainda que a tentativa ou a reorganização da estrutura familiar para se adequar a criança autista gera transtornos e por vezes inabilidades em se manter nessa estrutura.

O autismo infantil é, para a família, uma tarefa árdua, difícil, cansativa e, por vezes, dolorosa. Quando se planeja um filho, almeja-se uma criança perfeita e saudável. Nem mesmo cogitase a hipótese de essa criança nascer com qualquer limitação que seja. Quando a criança tão sonhada começa a apresentar características, como dificuldade ou demora para falar, comportamentos repetitivos e estereotipados e dificuldade de estabelecer relações de afeto e carinho, os sonhos idealizados sobre essa criança caem por terra e a família depara-se com uma realidade desconhecida, que poderá desconcertá-la e exigir uma nova organização família ${ }^{10}$.

Depreendem-se do estudo também as altas taxas de mães que referem dedicar-se exclusivamente à criança autista, deixando suas vidas profissionais e pessoais por acreditarem que, assim, terão maior possibilidade de prestar melhor assistência a essa criança.

O olhar do outro é mais um fator que influencia a vivência da maternidade. Ver que as pessoas ficam incomodadas com a presença da criança autista é sentido pelas mães como um gesto de preconceito. Ao se falar em autismo, é apontado que qualquer ofensa ao filho é sentida pela mãe como se fosse dirigido a ela própria. É, justamente, por perceber a fragilidade do filho diante do social que as mães também se sentem fragilizadas. Discriminar, ter preconceito ou até mesmo olhar de forma diferente para a criança mobiliza na mulher a vontade de proteger cada vez mais esse filho que, para ela, é uma criança indefesa. Assim, é devido a essa maior necessidade de proteção que as mães dedicam-se integralmente à maternidade ${ }^{11}$.

A restrição social de mães de autista é um fator identificado nos estudos como sendo significativo para a proteção da criança, buscando, dessa forma, manter o filho longe de olhares curiosos e discriminatórios, provocando sobre si o isolamento social. Os sentimento de culpa que, por vezes, podem ser experiências vividas por pais e cuidadores são fatores mencionados nos estudos como sendo importante colaborador para a reorganização familiar. No entanto, não são explicados claramente nos estudos analisados.

Os estudos analisados apontam que o Brasil ainda é referência ao modelo de família tradicional com o pai a mãe e a criança. Assim, o papel de cuidador fica mais direcionado à genitora, principalmente quando se trata de famílias com filhos especiais, fator que contribui de forma negativa quando avaliada a relação de trabalho e a dedicação à criança autista ficando assim com sobrecarga de atividades e tem a tendência de um isolamento social em virtude de sua criança.

Dizem que o autismo, quando se manifesta, afeta toda a família, pois o processo de enfrentamento desencadeia mudanças em toda a dinâmica familiar, em especial na relação mãe e filho ${ }^{10}$. As mães de crianças autistas, diante da situação de vulnerabilidade e de dependência do filho, passam a dedicar-se integralmente a eles, acumulando muitas responsabilidades, como os cuidados com a casa, com a família e ainda com o filho autista, o que acarreta grande sobrecarga emocional e física.

As consequências e limitações na vida pessoal do cuidador correspondem a um conjunto de situações, as quais podem provocar alterações e impacto na vida pessoal, como diminuição de tempo disponível, saúde afetada e, ainda, a necessidade de alterar um conjunto de hábitos para poder dar respostas às necessidades da família.

Para a família, deparar-se com as limitações da criança autista, por menor que seja, significa um encontro com o desconhecido. Enfrentar essa nova e inesperada realidade causa sofrimento, confusão, frustração e medo. Ser pai e mãe, neste momento, significa embarcar em uma experiência complexa, repleta de dificuldades e extremas responsabilidades, pois a criança pode ser parcial ou totalmente dependente dos pais ${ }^{12}$.

\section{Estrategia e intervenção}

Quando se apresenta estratégias no desenvolvimento do cuidar da criança autista, é inevitável se pensar nas práticas maternas e familiares apresentadas e praticadas ao autista. Estudos apresentados $^{11}$ apontam que é preciso olhar não só para o autista, mas também para a família, principalmente para a mãe, já que é ela quem assume as maiores responsabilidades com o filho no que se refere aos cuidados básicos diários.

Assim, as estratégias apresentadas tenham a possibilidade de 
trazer melhora significativas para a criança, bem como a suas mães e familiares em um espaço no qual possam ser escutados, trocar experiências, compartilhar sua dor e sofrimento e amenizar suas angústias e incertezas.

Diferentes autores ${ }^{13}$ apontam que as questões das terapias são apontadas como melhor forma de tratamento e acompanhamento das crianças autistas e de seus familiares. Além do grupo de terapia, as crianças autistas requerem acompanhamento por fonoaudiólogos, fisioterapeutas e psicólogos. As atividades físicas e recreativas como natação e equoterapia são apontadas como intervenções e estratégias para a melhora dos quadros graves de transtorno do desenvolvimento.

Nesse contexto, depreende-se que a interação social das crianças entre si e com os profissionais, por meio de atividades e brincadeiras desenvolvidas em conjunto, é capaz de desenvolver no autista possibilidades de mudanças de comportamento relacionadas às atividades da vida diária, em que as crianças são estimuladas a alimentar-se e ingerir líquidos, usar o banheiro, fazer higiene das mãos, calçar e amarrar os calçados de maneira independente.

Toda intervenção direcionada às dificuldades e ao tratamento da criança autista devem priorizar o apoio e a dedicação da família como fatores determinantes do desenvolvimento e da evolução da criança ao longo do processo terapêutico ${ }^{14}$.

A enfermagem, enquanto profissão cuja ferramenta principal de trabalho é o cuidado, deve focar sua atenção nas crianças autistas e suas mães, cujo sofrimento pode estar encoberto pelo próprio existir do filho. Essas mães necessitam de cuidado e atenção para que possam cuidar de seus filhos e de si mesmas, participando ativamente do processo de tratamento ${ }^{8}$.

As estratégias empregadas são identificadas como fator positivo no desenvolvimento cognitivo e interpessoal da criança autista. As intervenções aplicadas são vistas não somente para o tratamento, para a inclusão social, tanto das crianças quanto da família. A procura dos responsáveis por esses tipos de estratégias é movida pelo cuidado. Fator facilitador na interação social e familiar das crianças e seus cuidadores.

Não existem terapias mais ou menos apropriadas para o autismo, pois cada pessoa reage de maneira diferente às diversas formas de intervenção. Sabe-se que a etapa da vida na qual o autista se encontra interfere nos resultados da terapia, devendo ser substancialmente diferente o tipo de abordagem a ser realizado em cada etapa ${ }^{14}$.

\section{O desenvolvimento do cuidar empregado ao autista}

A divisão de trabalho relacionado ao cuidado da criança compreendia tarefas parentais como alimentação, organização de hábitos de higiene, transporte, auxílio em tarefas escolares e acompanhamento do filho em atividades recreativas ${ }^{15}$.
As autoras $^{15}$ identificam em seu estudo que, quando relacionado ao aspecto do cuidar entre os genitores, o pai se apresenta como um suporte para auxílio quando necessário nas atividades diárias. Enquanto a mãe é a detentora dos cuidados básicos de que a criança necessita como se alimentar, tomar banho, escovar os dentes, vestir-se e fazer higiene pessoal. As autoras também identificam que as atividades de transporte e saúde, na maioria dos casos, são realizadas por mães, sendo que elas se dedicam inteiramente ao cuidado do filho.

Quando relacionado à dificuldade em relação à dependência do filho, sua higiene e demais atividades que envolvam o toque, o contato físico, são atividades cotidianas de maior dificuldade citadas nos textos referenciando ativamente o constrangimento dos pais em cuidar da higiene íntima do filho quando a criança em questão é do sexo oposto.

As crianças com autismo, enquanto portadoras de uma condição crônica, enfrentam dificuldades importantes no que tange à realização de tarefas próprias de sua fase de desenvolvimento, porque as características clínicas motivam um aumento de sua demanda por cuidados e, consequentemente, de seu nível de dependência para com os pais e/ou cuidadores ${ }^{16}$.

Observa-se, em estudos ${ }^{17}$, que as mães agem de forma objetiva e prática, tomando iniciativas para resolver os problemas e demonstrando capacidade de manejo para lidar com seus filhos diante das circunstâncias estressoras surgidas no dia a dia, seja no convívio familiar seja no ambiente social mais amplo.

Os apontamentos levantados nas análises realizadas no banco de dados da pesquisa esclarecem que essas mães, em sua maioria, recebem apoio e orientação das escolas especiais, principalmente sobre o manejo com os filhos, o que talvez possa estar favorecendo uma maior utilização da estratégia de ação direta quanto a atividades diárias relacionadas ao filho. Porém, os estudos analisados não identificam as formas utilizadas para que as crianças, em questão, tornem-se adultos independentes que possam realizar de forma independente seu próprio cuidado.

\section{Melhora apresentada no desenvolvimento}

O entendimento em relação aos transtornos que envolve o paciente autista possibilita o desenvolvimento de pais e mães de autistas quanto de seus familiares. Observa-se, no estudo, que, apesar dos avanços de conhecimento em torno desse transtorno, ainda é muito inferior se mensurado com as necessidades de uma criança autista para seu crescimento e desenvolvimento.

As crianças com autismo, enquanto portadoras de uma condição crônica, enfrentam dificuldades importantes no que tange à realização de tarefas próprias de sua fase de desenvolvimento, porque as características clínicas motivam um aumento de sua demanda por cuidados e, consequentemente, de seu nível de dependência para com os pais e/ou cuidadores ${ }^{16}$. 
O ambiente escolar é outra referência importante para os pais de autistas. As interações escolares são apontadas no estudo ${ }^{11}$, como forma de integrar a criança à sociedade. Identifica-se, no estudo, a questão que integrar a criança na comunidade é um momento gerador de crise, pois já, nas primeiras saídas, em locais onde estão outras crianças, é perceptível para os pais o surgimento da rejeição social, bem como mudanças de comportamento da criança portadora de autismo.

Por isso, o momento da entrada do filho na escola poderia ser um fator de melhora em seu desenvolvimento; também se materializa na questão da diferença e dos limites em relação à aprendizagem dessa criança podendo levar a angústia por parte dos pais que, por muitas vezes, optam por manter a educação do filho no ambiente familiar ${ }^{18}$.

Fatores que apontam para a independência da criança autista, que possam identificar seu domínio em suas condições e desenvolvimento do seu próprio cuidado não foram identificadas nos estudo. Identifica-se também que as mães têm a necessidade de realizar todas as atividades nas quais as crianças poderiam mostrar controle. Contudo, os fatores relacionados aos sentimentos de culpa são identificados como primordiais para que essas crianças tenham suas atividades realizadas por seus pais ou cuidadores.

\section{CONCLUSÃO}

Por meio deste estudo, identifica-se que a vivência de familiares e cuidadores de crianças com transtorno do desenvolvimento têm suas vidas e sua organização familiar afetada diretamente pela adequação pretendida para seus filhos buscando-se evitar sofrimento a essas crianças, passando a vivenciar inteiramente o cotidiano do filho, podendo influenciar negativamente no desenvolvimento das ações dessas crianças.

Constata-se, ainda, a necessidade da construção de um conhecimento mais sólido por parte da enfermagem, para que possa instituir um cuidado mais efetivo, tanto às crianças autistas como a seus familiares. Contudo, ressalta-se que ainda há muito a ser desvelado; por isso, a importância e necessidade de novos estudos que visem ao desenvolvimento de atividades empregando o desenvolvimento do autocuidado das crianças em busca de perspectiva de futuro.

Contudo, depreende-se do estudo a necessidade de mostrar aos familiares e especificamente à genitora, a necessidade de estimular a criança para seu próprio cuidado de acordo com suas fases de crescimento e desenvolvimento, realizando a divisão de tarefas com os demais membros da família envolvidos com a criança, por mais que os instintos maternos protetores aflorem quando avaliadas as necessidades da criança autista.

\section{REFERÊNCIAS}

1. Gomes VF, Bosa C. Estresse e relações familiares na perspectiva de irmãos de indivíduos com transtornos globais do desenvolvimento. Estud. psicol. 2004 SetDez; 9(3), 553-561. doi: http://dx.doi.org/10.1590/S1413-294X2004000300018

2. Ministério da Saúde [BR], Secretaria de Atenção à Saúde, Departamento de Ações Programáticas Estratégica. Caminhos para uma política de saúde mental infanto-juvenil. 2. ed. Brasília: Ministério da Saúde; 2005.

3. Associação Americana de Psiquiatria. DSM-V: manual e diagnóstico e estatístico de transtornos mentais. Porto Alegre: Artmed; 2013.

4. Segeren L, Françozo MFC. As vivências de mães de jovens autistas. Psicol. estud. 2014 Jan-Mar; 19(1): 39-46. doi: http://dx.doi.org/10.1590/14137372189590004.

5. Cezar PK, Smeha LN. Repercussões do autismo no subsistema fraterno na perspectiva de irmãos adultos. Estud psicol.. 2016 Jan-Mar; 33(1) 51-60. doi: http://dx.doi.org/10.1590/1982-02752016000100006

6. Bezanilla JM, Ruiz AT, Miranda MA. Primera Aproximación Sociométrica al Grupo Canguro de nível escolar. Research Gate. 2014 Jun.

7. Nunes AMF, Santos MA. Itinerário terapêutico percorrido por mães de crianças com transtorno autístico. Psicol. Reflex. Crít. 2010. 23(2): 208-221. doi: http://dx.doi.org/10.1590/S0102-79722010000200003.

8. Monteiro CFS, Batista DONM, Moraes EGC, Magalhães TS, Nunes BMVT, Moura MEB. Vivências maternas na realidade de ter um filho autista: uma compreensão pela enfermagem. Rev Bras Enferm. 2008 Maio-Jun; 61(3):33035.

9. Mendes KDS, Silveira RCCP, Galvão CM. Revisão integrativa. Método de pesquisa para a incorporação de evidencias na saúde e na enfermagem. Texto contexto - enf. 2008 Out-Dez; 10(4):758-764. doi: http://dx.doi.org/10.1590/ S0104-07072008000400018.

10. Zanatta EA, Menegazzo E, Guimarães AN, Ferraz L, Motta MGC. Cotidiano de famílias que convivem com o autismo infantil. Rev Baiana de Enfermagem. 2014 Set-Dez; 28(3) 271-282.

11. Smeha LN, CezaR PK. A Vivência da maternidade de mães de crianças com autismo. Psicol. estud. 2011 Mar; 16(1). 43-50. doi: http://dx.doi.org/10.1590/ S1413-73722011000100006.

12. Buscaglia L. Os deficientes e seus pais: um desafio ao aconselhamento. Rio de Janeiro: Record; 2006.

13. Koegel RL, Schreibman L, Loos LM, Dilrich-Wilhelm H, Dunlap G, Robbins R et al. Consistent stress profiles in mothers of children with autism. J Autism Dev Disord. 1992 Jun; 22(2): 205-216. PubMed PMID: 1624405.

14. Simões ALA, Rodrigues LR, Fonseca MO, Machado DC, Amaral AS. Significado da terapia de grupo para crianças autistas: percepção das mães. Cienc Cuid Saúde. 2010 Abr-Jun; 9(2):278-284. doi: 10.4025/cienccuidsaude.v9i2.8844

15. Sifuentes M, Bosa CA. Criando pré-escolares com autismo: características e desafios da coparentalidade. Psicol. estud; 2010 Jul-Set; 15(3): 477-485.

16. Schmidt C. Estresse, auto eficácia e o contexto de adaptação familiar de mães de portadores de transtornos globais do desenvolvimento. [dissertação]. Porto Alegre: Universidade Federal do Rio Grande do Sul; 2002.

17. Weiss SJ. Stressors experienced by family caregivers of children of pervasive developmental disorders. Child Psychiatry and Human Development. 1991 Mar; 21(3): 203-216. 
341 A família de uma criança autista

18. Silva LWS, Francione FF; Sena ELS, Carraro TE, Randiniz VO. Cuidado na

enfermagem. Rev. bras enferm. 2005; 58(4): 471- 475. doi: http://dx.doi. perspectiva de Leonardo Boff: uma personalidade a ser(re)descoberta na org/10.1590/S0034-71672005000400018.

Como citar este artigo/How to cite this article:

Silva SED, Santos AL, Sousa YM, Cunha NMF, Costa JL, Araújo JS. A família, o cuidar e o desenvolvimento da criança autista. J Health Biol Sci. 2018 Jul-Set; 6(3):334-341.

J. Health Biol Sci. 2018; 6(3): 334-341 